\title{
Changing trends and emissions of hydrochlorofluorocarbons (HCFCs) and their hydrofluorocarbon (HFCs) replacements
}

Peter G. Simmonds et al.

Correspondence to: Peter G. Simmonds (petergsimmonds@aol.com)

The copyright of individual parts of the supplement might differ from the CC-BY 3.0 licence. 
Table S1. Global HCFC and HFC emissions fluxes (Gg/yr) estimates from the AGAGE 12box model.

\begin{tabular}{lcccccccc}
\hline & HCFC-22 & HCFC-141b & HCFC-142b & HCFC-124 & HFC-125 & HFC-134a & HFC-143a & HFC- 32 \\
\hline $\mathbf{1 9 9 5}$ & 233.7 & 39.0 & 24.4 & & 2.1 & 20.0 & 2.1 & \\
$\mathbf{1 9 9 6}$ & 224.1 & 47.5 & 29.4 & & 3.5 & 31.9 & 3.3 & \\
$\mathbf{1 9 9 7}$ & 232.3 & 50.0 & 30.1 & & 5.7 & 39.7 & 4.4 & 0.15 \\
$\mathbf{1 9 9 8}$ & 265.6 & 55.4 & 27.4 & & 6.3 & 60.3 & 5.5 & 0.14 \\
$\mathbf{1 9 9 9}$ & 251.2 & 58.9 & 29.6 & & 6.5 & 70.2 & 6.6 & 0.48 \\
$\mathbf{2 0 0 0}$ & 272.6 & 62.6 & 31.6 & 4.4 & 8.5 & 79.6 & 8.3 & 0.99 \\
$\mathbf{2 0 0 1}$ & 271.7 & 55.9 & 28.8 & 6.4 & 9.3 & 86.2 & 8.6 & 1.4 \\
$\mathbf{2 0 0 2}$ & 276.7 & 62.0 & 25.6 & 7.3 & 11.2 & 99.9 & 9.3 & 1.9 \\
$\mathbf{2 0 0 3}$ & 284.0 & 57.5 & 26.5 & 7.3 & 13.9 & 109.6 & 11.3 & 2.7 \\
$\mathbf{2 0 0 4}$ & 289.3 & 49.6 & 25.5 & 6.2 & 14.5 & 117.7 & 12.0 & 4.2 \\
$\mathbf{2 0 0 5}$ & 308.4 & 46.2 & 28.9 & 6.3 & 17.1 & 126.3 & 14.0 & 5.5 \\
$\mathbf{2 0 0 6}$ & 333.6 & 51.3 & 34.2 & 6.0 & 19.5 & 128.4 & 15.6 & 6.8 \\
$\mathbf{2 0 0 7}$ & 352.1 & 53.8 & 37.0 & 6.0 & 21.9 & 137.6 & 16.1 & 8.4 \\
$\mathbf{2 0 0 8}$ & 370.3 & 54.2 & 39.4 & 5.1 & 26.4 & 148.5 & 18.5 & 9.7 \\
$\mathbf{2 0 0 9}$ & 364.0 & 52.8 & 35.0 & 4.4 & 28.0 & 154.8 & 18.7 & 11.7 \\
$\mathbf{2 0 1 0}$ & 382.8 & 60.5 & 35.2 & 4.2 & 35.5 & 169.1 & 20.5 & 15.0 \\
$\mathbf{2 0 1 1}$ & 370.5 & 67.1 & 32.8 & 4.2 & 39.8 & 171.5 & 21.6 & 18.1 \\
$\mathbf{2 0 1 2}$ & 369.8 & 68.4 & 29.1 & 4.1 & 44.5 & 177.2 & 23.1 & 21.1 \\
$\mathbf{2 0 1 3}$ & 365.5 & 64.5 & 26.6 & 3.2 & 49.8 & 186.4 & 24.3 & 24.4 \\
$\mathbf{2 0 1 4}$ & 369.7 & 63.0 & 25.2 & 3.4 & 57.3 & 199.5 & 25.6 & 28.9 \\
$\mathbf{2 0 1 5}$ & 360.6 & 60.2 & 24.8 & 3.3 & 59.7 & 209.0 & 27.4 & 31.2 \\
\hline
\end{tabular}

\section{Supplementary Material: Calculation of Quantities Emitted using HCFC Consumption} Data.

Consumption data for HCFCs are published only in aggregate, as the total quantity of all HCFCs, by the Montreal Protocol Secretariat of the United Nations Environment Programme [UNEP, 2016]. However, between 1990 and 2011, values for annual consumptions of HCFCs $-22,-141 b$ and $-142 b$, individually, were provided in Figure 1.26 of Carpenter and Reimann, (2014). These constitute virtually all of the HCFCs consumed, as shown in Figure S1 comparing the sum of the data in Carpenter and Reimann, (2014) with the global total of HCFCs from UNEP (2016). 


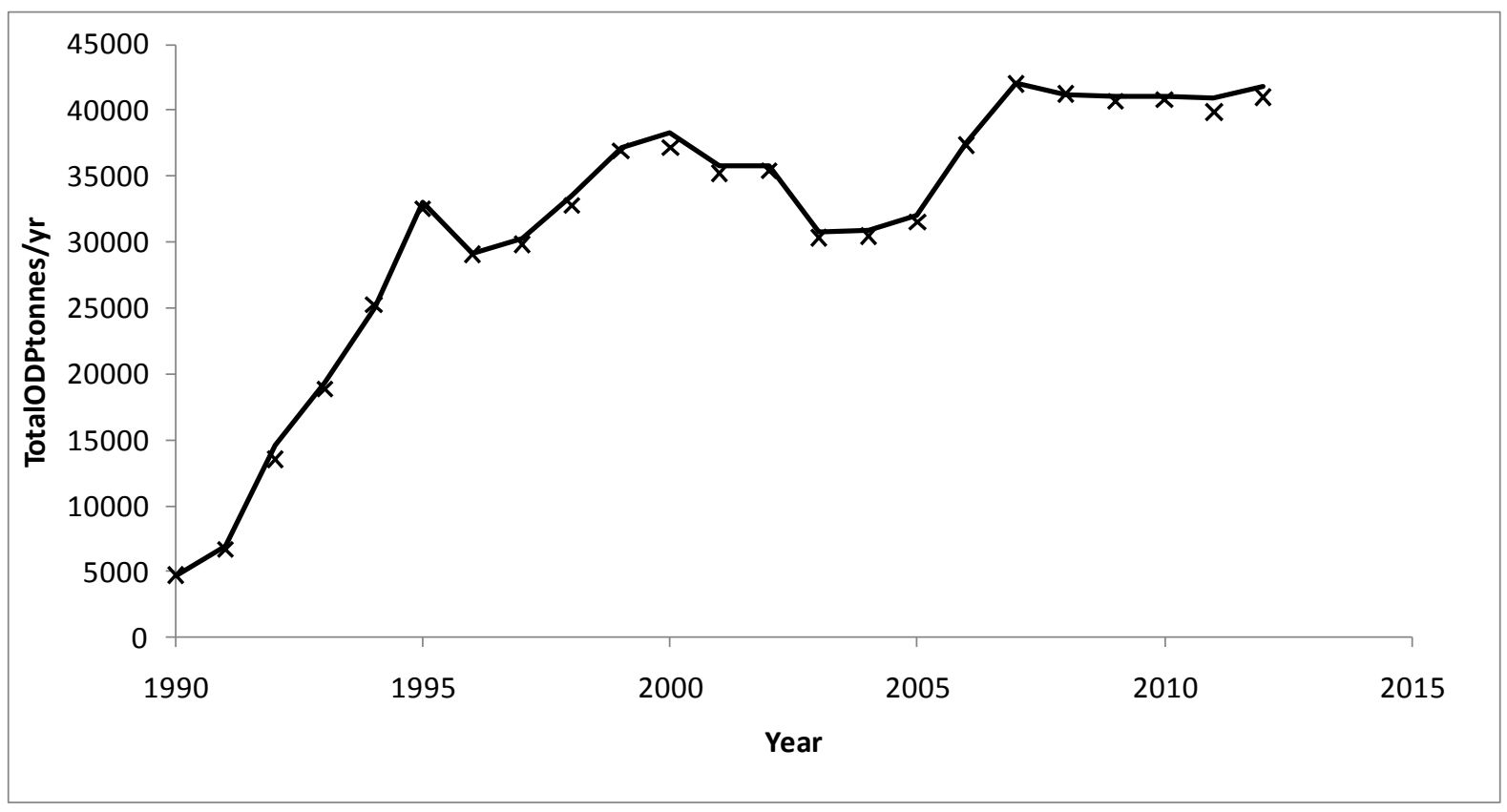

Figure S1. Comparison between HCFC global consumption databases expressed as mass multiplied by ozone depletion potential (ODP tonnes). Crosses are the totals of annual consumption of HCFC-22, HCFC-141b and HCFC-142b from Carpenter and Reimann. (2014). Solid line is the total consumption of all Group C1 substances (HCFCs) reported under the Montreal Protocol (UNEP, 2016)

The differences between the points and the solid line show that the contribution from other HCFCs, such as HCFC-123 and HCFC-124 is very small (less than 2\%, on average). Consequently, although the values in Carpenter and Reimann (2014) do not extend beyond 2011, it was possible to extrapolate them for the three years to 2014 based on the annual totals and the prior contributions of individual HCFCs.

\section{$\underline{\text { Emissions }}$}

Emissions of substances used in refrigeration or foam blowing generally conform to the pattern:

Initial loss, followed by loss during service and finally loss at disposal of the equipment containing the substance. (Ashford et al., 2004)

Values relevant to the most common uses of HCFCs-22, $-141 \mathrm{~b}$ and $-142 \mathrm{~b}$ are shown in Table S2.

In order to apply the emission functions provided by Ashford et al., (2004), information on the individual categories of end use would be required. The values from Carpenter and Reimann (2014) are for total consumption and so the best that can be accomplished is a consistency test of these functions against emissions calculated from atmospheric measurements. These "measured" emissions compiled from this study are shown as the crosses in Figures S2-S4. 
Table S2. Emission functions expressed as loss rates, all data in percentages.

\begin{tabular}{|c|c|c|c|c|c|c|c|}
\hline & \multicolumn{5}{|c|}{ Ashford et al., 2004} & \multicolumn{2}{|c|}{ This work } \\
\hline & \multicolumn{2}{|c|}{ Short term } & \multicolumn{3}{|c|}{ Medium to long term } & \multirow{2}{*}{$\begin{array}{l}\text { Initial } \\
( \pm 1 \mathrm{~s} . \\
\text { dev. })\end{array}$} & \multirow{2}{*}{$\begin{array}{c}\text { Annual } \\
\text { loss from } \\
\text { bank }\end{array}$} \\
\hline & First year & $\begin{array}{l}\text { Next } \\
\text { year }\end{array}$ & Initial & Annual & $\begin{array}{l}\text { Main } \\
\text { use }^{*}\end{array}$ & & \\
\hline HCFC-22 & 83 & 17 & 37 & 6.3 & RAC & $41.3 \pm 5.8$ & 9.8 \\
\hline HCFC-141b & 83 & 17 & 15 & 4.5 & $\mathrm{CCF}$ & $34.5 \pm 4.0$ & 2.2 \\
\hline HCFC-142b & 83 & 17 & 33 & 3 & $\mathrm{CCF}$ & $30.0 \pm 6.8$ & 12.9 \\
\hline
\end{tabular}

* RAC represents refrigeration and air conditioning and CCF represents closed cell foam blowing.

Given the general form of the loss pattern in the historic data, it was postulated that emissions from total annual consumptions could be described as an initial loss plus a constant function of the bank remaining in equipment. Similar methodology has been used to examine the history of reported European emissions (McCulloch, 2009; McCulloch and Vink, 2010), in which it was demonstrated that the loss rate from the bank reduced towards a constant rate over several years after consumption commenced. Thus

$\mathrm{E}_{y}=\mathrm{Ix} \mathrm{C}_{y}+\mathrm{FxB}_{y}$

where $\mathrm{E}$ is the mass emitted, $\mathrm{I}$ is the initial loss factor (\%), $\mathrm{C}$ is the mass consumed and $\mathrm{F}$ is the annual emission factor from the bank $\mathrm{B}$, all in year $y$.

The quantity in the bank each year being given by:

$\mathrm{B}_{y}=\mathrm{B}_{y-1}+\mathrm{C}_{y}-\mathrm{E}_{y}$

That is, the bank at the end of year $y$ is equal to the previous year's bank plus the excess of consumption over emission for year $y$.

The equations were solved using the global emissions estimates reported in this study and the global consumption data in Carpenter and Reimann (2014), over the period 1995 to 2014, for a series of emission functions from the bank to give a series of initial loss rates and their standard deviations. The annual banks were calculated explicitly, starting from the banks for each compound in the AFEAS database in 1990 (AFEAS, 2016). Table S2 shows the values from these series with the lowest standard deviations of the initial losses. These are compared with the typical historic emission functions in Ashford et al (2004).

For HCFCs -22 and $-142 \mathrm{~b}$, although the initial loss rates are similar to those previously estimated, long term emissions from the predominant uses are significantly faster. The rate of emission of HCFC-22 from the bank is 50\% greater and that of HCFC-142b is greater by a factor of four. Consequently, the trends in emissions follow trends in consumption more closely than would have been expected from Ashford et al. (2004).

Conversely, for HCFC-141b the initial loss rate is significantly greater than that proposed by Ashford et al. (2004) for the predominant use in foam blowing, with the possible inference of larger than expected use in short term release categories (such as solvent or cleaning agent). 
Furthermore, long term loss rates are half those previously assigned to foam blowing, calling into question the previous foam loss function.

Notwithstanding these, it appears that an initial loss with subsequent constant loss from the bank at a relatively low rate constitutes a viable model. Figures S2 to S4 show the range of annual emissions fluxes calculated using the values in Table S2, compared to the emissions calculated from atmospheric measurements and the consumption record. Mean values of these emissions are shown in Table 3.

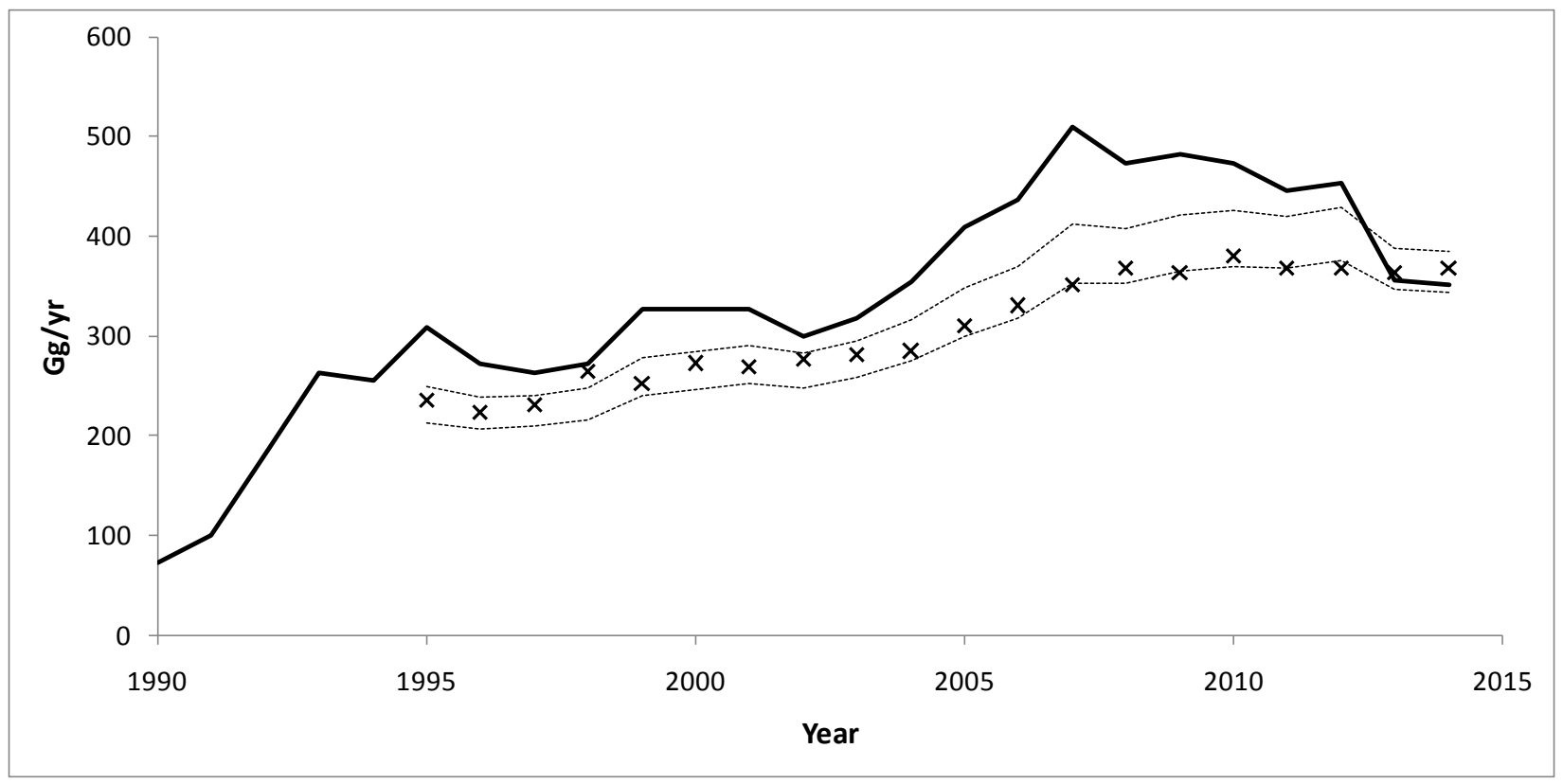

Figure S2. Annual consumptions of HCFC-22 from Carpenter and Reimann (2014) (solid line), with annual emissions fluxes from atmospheric data $(\mathrm{X})$ and the range of emissions calculated from consumption data (mean $\pm 1 \sigma)$ (dotted lines).

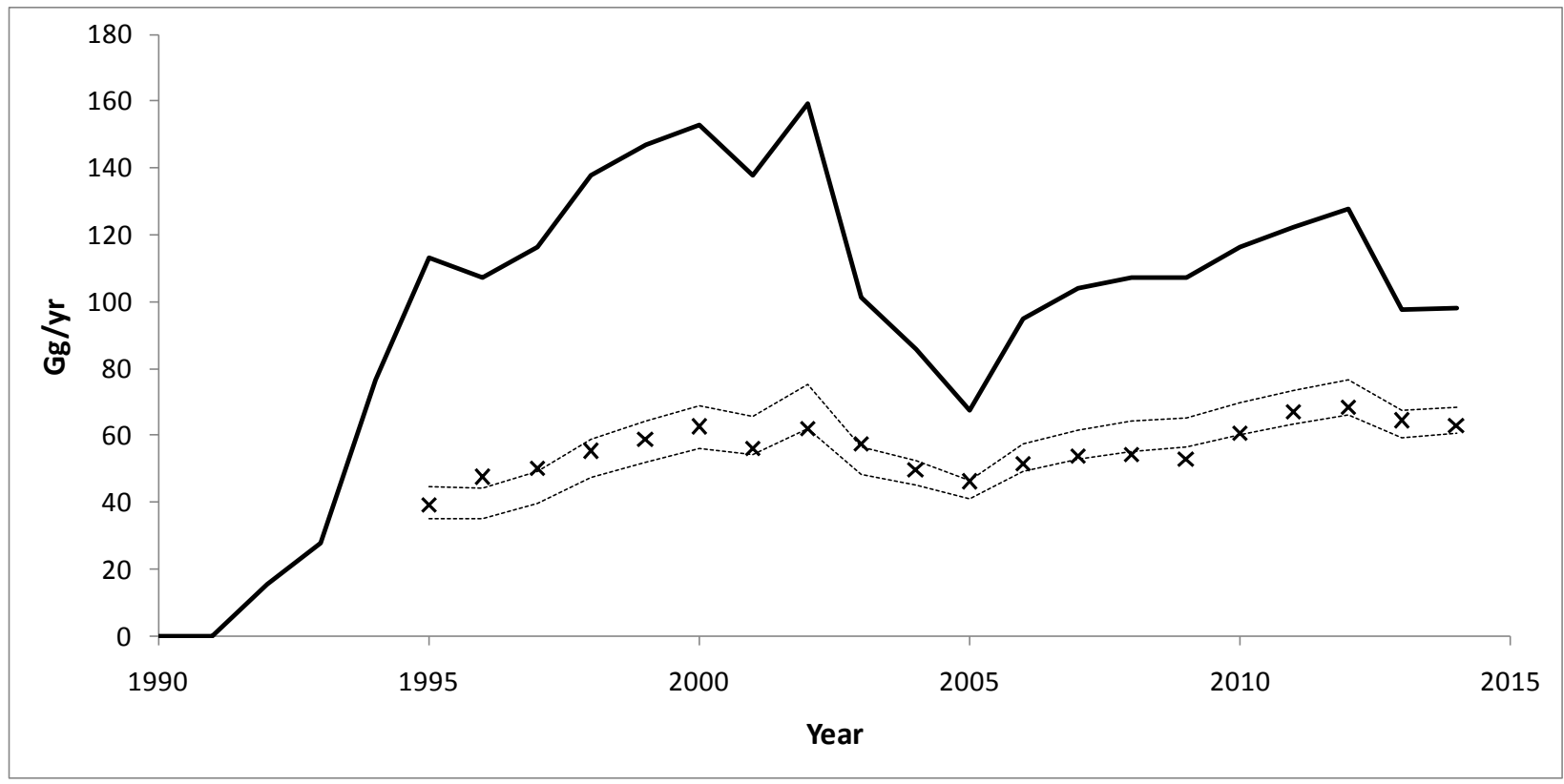


Figure S3. Annual consumptions of HCFC-141b from Carpenter and Reimann (2014) (solid line), with annual emissions fluxes from atmospheric data $(X)$ and the range of emissions calculated from consumption data (mean $\pm 1 \sigma)$ (dotted lines).

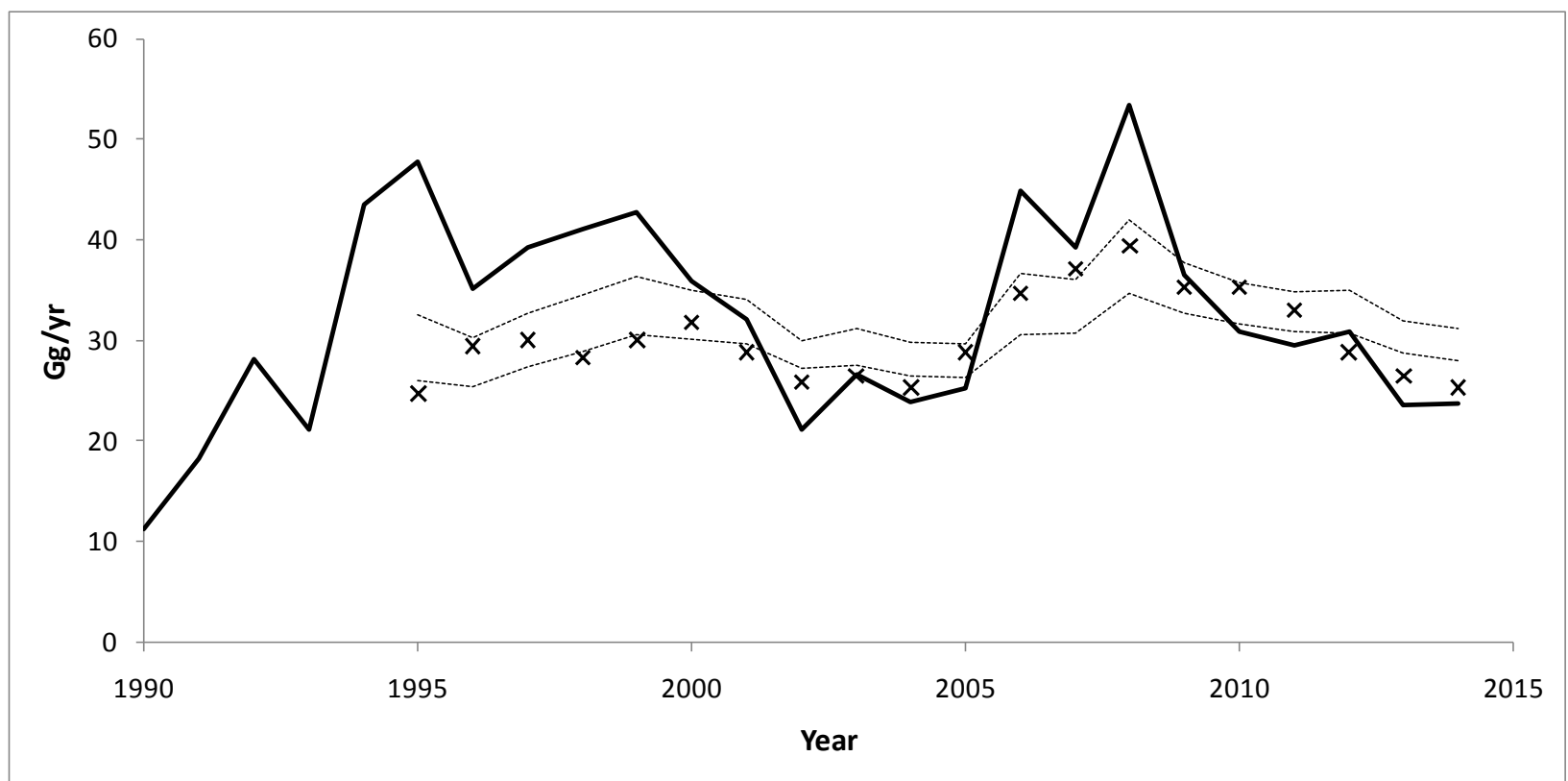

Figure S4. Annual consumptions of HCFC-142b from Carpenter and Reimann (2014) (solid line), with annual emissions fluxes from atmospheric data $(X)$ and the range of emissions calculated from consumption data (mean $\pm 1 \sigma)$ (dotted lines). 
Table S3. Mean annual emissions fluxes of HCFCs calculated from consumption data.

\begin{tabular}{cccc} 
& \multicolumn{3}{c}{ Emission Gg/yr } \\
\cline { 2 - 4 } Year & HCFC- & HCFC- & HCFC- \\
& 22 & $141 \mathrm{~b}$ & $142 \mathrm{~b}$ \\
1995 & 230.4 & 42.1 & 29.2 \\
1996 & 223.1 & 41.5 & 27.8 \\
1997 & 224.2 & 46.1 & 30.0 \\
1998 & 231.9 & 55.1 & 31.7 \\
1999 & 258.4 & 60.1 & 33.4 \\
2000 & 265.1 & 64.1 & 32.6 \\
2001 & 271.2 & 60.8 & 31.8 \\
2002 & 265.5 & 69.8 & 28.6 \\
2003 & 276.3 & 51.7 & 29.3 \\
2004 & 295.4 & 47.6 & 28.1 \\
2005 & 323.7 & 42.1 & 28.0 \\
2006 & 343.4 & 52.1 & 33.5 \\
2007 & 382.5 & 56.2 & 33.3 \\
2008 & 379.9 & 58.3 & 38.3 \\
2009 & 392.7 & 59.4 & 35.2 \\
2010 & 397.7 & 63.6 & 33.7 \\
2011 & 393.8 & 66.9 & 32.9 \\
2012 & 402.4 & 69.9 & 32.9 \\
2013 & 366.7 & 60.8 & 30.4 \\
2014 & 363.8 & 61.8 & 29.6
\end{tabular}

Supplementary Material: Reconciliation of the Quantities of Individual HFCs Released with the Compositions of Refrigerant Blends

- HFCs $-32,-125$ and -143 a are used in refrigerant blends. It is assumed that this is their main use, although there is some HFC-125 that is also used in fire suppression systems.

- The blends, by weight $\%$, are:

\begin{tabular}{llllllll}
\hline & R-404A & R-407A & R-407C & R-407F & R-410A & R-438A & R-507A \\
\hline $\mathbf{1 2 5}$ & 44 & 40 & 25 & 30 & 50 & 45 & 50 \\
$\mathbf{1 3 4 a}$ & 4 & 40 & 52 & 40 & & 44.2 & \\
$\mathbf{1 4 3 a}$ & 52 & & & & & & 50 \\
32 & & 20 & 23 & 30 & 50 & 8.5 & \\
GWPs* & 3943 & 1923 & 1624 & 1674 & 1923 & 2059 & 3985 \\
\hline
\end{tabular}

* GWPs from (Myhre and Shindell. 2013)

- We can assume that most (almost all) of the HFC-143a is used in R-404A. Hence the emission of R-404A can be calculated from the HFC-143a emission, leading to a value for the HFC-125 emitted as R-404A.

- The actual emission of HFC-125 minus that in R-404A (residual HFC-125) is the result of:

- emission of R-407A and/or

- emission of R-407C, R-407F and R-410A (which could be counted as R410A) and/or 
○ emission of HFC-125, on its own.

- We have two sources of data - UNFCCC (which is NOT global and covers only developed countries) and global values from this study of AGAGE data.

\section{$\underline{\text { UNFCCC Data }}$}

\begin{tabular}{|c|c|c|c|c|c|c|c|}
\hline \multirow{4}{*}{ Year } & \multicolumn{7}{|c|}{ UNFCCC (all data Gg) } \\
\hline & \multirow{2}{*}{$\begin{array}{l}\mathrm{R}-404 \mathrm{~A} \\
\text { based on }\end{array}$} & \multirow[b]{2}{*}{ Residual } & \multirow[b]{3}{*}{ HFC-32 } & \multicolumn{4}{|c|}{ HFC-125 } \\
\hline & & & & \multicolumn{2}{|c|}{ Maximum R-407A } & \multicolumn{2}{|c|}{ Maximum R-410A } \\
\hline & HFC-143a & HFC-125 & & Needed & Excess & Needed & Excess \\
\hline 2000.5 & 5.5 & 1.8 & 0.3 & 0.5 & 1.3 & 0.3 & 1.5 \\
\hline 2001.5 & 6.7 & 2.0 & 0.4 & 0.9 & 1.1 & 0.4 & 1.6 \\
\hline 2002.5 & 8.0 & 2.1 & 0.6 & 1.3 & 0.9 & 0.6 & 1.5 \\
\hline 2003.5 & 9.5 & 2.4 & 0.9 & 1.9 & 0.5 & 0.9 & 1.5 \\
\hline 2004.5 & 10.7 & 2.8 & 1.4 & 2.7 & 0.1 & 1.4 & 1.4 \\
\hline 2005.5 & 12.3 & 3.3 & 1.9 & 3.8 & -0.5 & 1.9 & 1.4 \\
\hline 2006.5 & 13.4 & 4.2 & 2.9 & 5.7 & -1.5 & 2.9 & 1.4 \\
\hline 2007.5 & 14.8 & 5.4 & 4.0 & 8.0 & -2.5 & 4.0 & 1.5 \\
\hline 2008.5 & 16.1 & 6.7 & 5.1 & 10.3 & -3.6 & 5.1 & 1.6 \\
\hline 2009.5 & 17.7 & 8.2 & 6.3 & 12.6 & -4.4 & 6.3 & 1.9 \\
\hline 2010.5 & 19.8 & 10.4 & 8.3 & 16.5 & -6.1 & 8.3 & 2.2 \\
\hline 2011.5 & 21.6 & 12.6 & 10.3 & 20.6 & -8.0 & 10.3 & 2.3 \\
\hline 2012.5 & 23.1 & 15.1 & 12.6 & 25.3 & -10.2 & 12.6 & 2.4 \\
\hline 2013.5 & 24.8 & 17.5 & 15.2 & 30.4 & -12.8 & 15.2 & 2.4 \\
\hline $\begin{array}{l}2014.5 \\
2015.5\end{array}$ & & & & & & & \\
\hline
\end{tabular}

- If all of the HFC-125 emission were as R-407A, the quantity required would be twice that of the HFC-32 emission; similarly if all were as R-410A, the value would be the same as the HFC-32 emission.

- A positive value for the excess could indicate emission of HFC-125 on its own and a negative value could show that HFC-32 was emitted on its own.

- Up to 2005, the HFC-125 emissions exceed any that could be accountable to blends.

- However, from then on, the numbers are consistent with release of both R-407A and R-410A, without any need for emission of HFC-32 on its own.

- Depending on the extent to which HFC-125 is emitted on its own, the figures show a steady fall in the fraction of R407A, from about $70 \%$ in 2005 , to $16 \%$ in 2013. 


\section{AGAGE Data}

\begin{tabular}{|c|c|c|c|c|c|c|c|c|}
\hline \multirow{4}{*}{ Year } & \multicolumn{7}{|c|}{ Emissions $(\mathrm{Gg})$ calculated from AGAGE measurements } & \multirow{4}{*}{$\begin{array}{l}\text { R407A } \\
\text { content }\end{array}$} \\
\hline & \multirow{3}{*}{$\begin{array}{l}\text { R-404A } \\
\text { based on } \\
\text { HFC-143a }\end{array}$} & \multirow{3}{*}{$\begin{array}{l}\text { Residual } \\
\text { HFC-125 }\end{array}$} & \multirow[b]{3}{*}{ HFC-32 } & \multicolumn{4}{|c|}{ HFC-125 } & \\
\hline & & & & \multicolumn{2}{|c|}{ Maximum R-407A } & \multicolumn{2}{|c|}{ Maximum R-410A } & \\
\hline & & & & Needed & Excess & Needed & Excess & \\
\hline 2000.5 & 16.0 & 1.4 & 1.0 & 2.0 & -0.6 & 1.0 & 0.4 & $42 \%$ \\
\hline 2001.5 & 16.5 & 2.0 & 1.4 & 2.7 & -0.7 & 1.4 & 0.7 & $49 \%$ \\
\hline 2002.5 & 17.9 & 3.3 & 1.9 & 3.7 & -0.4 & 1.9 & 1.5 & $79 \%$ \\
\hline 2003.5 & 21.8 & 4.3 & 2.7 & 5.4 & -1.1 & 2.7 & 1.6 & $59 \%$ \\
\hline 2004.5 & 23.0 & 4.4 & 4.2 & 8.4 & -4.0 & 4.2 & 0.2 & $5 \%$ \\
\hline 2005.5 & 26.9 & 5.3 & 5.5 & 11.0 & -5.7 & 5.5 & -0.2 & $-4 \%$ \\
\hline 2006.5 & 30.0 & 6.3 & 6.8 & 13.6 & -7.3 & 6.8 & -0.5 & $-8 \%$ \\
\hline 2007.5 & 30.9 & 8.3 & 8.4 & 16.7 & -8.5 & 8.4 & 0.0 & $-1 \%$ \\
\hline 2008.5 & 35.6 & 10.8 & 9.7 & 19.4 & -8.7 & 9.7 & 1.0 & $11 \%$ \\
\hline 2009.5 & 35.9 & 12.2 & 11.7 & 23.4 & -11.1 & 11.7 & 0.5 & $4 \%$ \\
\hline 2010.5 & 39.5 & 18.2 & 15.0 & 30.1 & -11.9 & 15.0 & 3.1 & $21 \%$ \\
\hline 2011.5 & 41.6 & 21.5 & 18.1 & 36.2 & -14.6 & 18.1 & 3.4 & $19 \%$ \\
\hline 2012.5 & 44.4 & 25.0 & 21.0 & 42.1 & -17.2 & 21.1 & 3.9 & $19 \%$ \\
\hline 2013.5 & 46.7 & 29.3 & 24.4 & 48.9 & -19.6 & 24.4 & 4.8 & $20 \%$ \\
\hline 2014.5 & 49.2 & 35.7 & 28.9 & 57.8 & -22.1 & 28.9 & 6.8 & $23 \%$ \\
\hline 2015.5 & 52.7 & 36.5 & 31.2 & 62.4 & -26.0 & 31.2 & 5.3 & $17 \%$ \\
\hline
\end{tabular}

- These results are consistent with release of both R-407A and R-410A over the whole of the period.

- The apparent negative values for excess R-410A in 2005 to 2007 are too small to be significant.

- Of more concern is the variability of the R-407A fraction. It is possible that this shows three regimes - up to 2003, 2004 to 2009 and 2009 onwards although this is uncertain. Our conclusion is that the data are consistent with the proposition that the HFCs -32, 125 and -143 a found in the atmosphere were released as blends.

- Because the GWPs of R-407A and R-410A are identical (1923, 100-yr integration), the distribution of emissions between these two blends has little effect on their climate impacts.

\section{$\underline{\text { References }}$}

AFEAS (Alternative Fluorocarbons Environmental Acceptability Study) (2016), Production and Use of Fluorocarbons, at afeas.org, accessed May 2016.

Ashford P., Clodic, D., McCulloch, A, and Kuijpers, L. (2004), Emission profiles from the foam and refrigeration sectors comparison with atmospheric concentrations. Part 1:

Methodology and data, International Journal of Refrigeration 27, 687-700.

Carpenter, L. and Reimann, S., (Lead Authors), Burkholder, J., Clerbaux, C., Hall, B., Hossaini, R., Laube, J., Yvon-Lewis, S., (Co-authors), Blake, D., Dorf, M., Dutton, G., Fraser, P., Froidevaux, L., Hendrick, F., Hu, J., Jones, A., Krummel, P., Kuijpers, L., Kurylo, M., Laing, Q., Mahieu, E., Muhle, J., O’Doherty, S., Ohnishi, K., Orkin, V., Pfeilsticker, K., Rigby, M., Simpson, I., and Yokouchi, Y. (Contributing Authors), Update on OzoneDepleting Substances (ODSs) and Other Gases of Interest to the Montreal Protocol, Chapter 1 in Scientific Assessment of Ozone Depletion: 2014, Global Ozone Research and Monitoring 
Project - Report No. 55, 1.1-1.101, World Meteorological Organization, Geneva, Switzerland, 2014.

Harris, N. R. P. and D. J. Wuebbles (Lead Authors), Daniel, J.S., Hu, J., Kuijpers, L. J. M., Law, K. S.A., Prather, M. J and Schofield, R. Scenarios and Information for Policymakers, Chapter 5 in Scientific Assessment of Ozone Depletion: 2014, Global Ozone Research and Monitoring Project - Report No. 55, 5.1-5.58, World Meteorological Organization, Geneva, Switzerland, 2014.

McCulloch, A. (2009), Evidence for improvements in containment of fluorinated hydrocarbons during use: an analysis of reported European emissions, Environmental Science and Policy 12, $149-156$.

McCulloch, A. and Vink, T., (2010), Analysis of reported European emissions shows improvement in containment of hydrofluorocarbons, J. Integrative Environmental Sciences, Special Issue: Non-CO2 Greenhouse Gases, 7, Supp. 1, 21-29, doi: 10.1080/19438151003621318.

Reimann. S., Schaub, D., Stemmler, K., Folini, D., Hill, M., Hofer, P., Buchmann, B., Simmonds, P.G., Greally, B.R., and O'Doherty, S, (2004). Halogenated greenhouse gases at the Swiss high alpine site of Jungfraujoch (3580 $\mathrm{m}$ asl): Continuous measurements and their use in regional European source allocation. J. Geophys. Res, 109, D05307, doi:10.1029/2003JD003923, 2004.

Rigby, M., R.G. Prinn, R.G., O’Doherty, S., Miller, B.R., Ivy, D., Mühle, J., Harth, C., Salameh, P.K., Arnold, T.,Weiss, R.F., Krummel, P.B., Steele, L.P., Fraser, P.J., Young, D., and Simmonds, P.G., (2014). Recent and Future Trends in Synthetic Greenhouse Gas Radiative Forcing. Geophys. Res. Lett., 41, 2623-2630.

UNEP (2016), Data Centre of the Montreal Protocol Secretariat on http://ozone.unep.org/en/data-reporting/data-centre, accessed May 2016. 


\section{Supplementary Material: Comparison of NOAA and AGAGE HCFC and HFC measurements at common sites.}

The NOAA Earth System Research Laboratory/Global Monitoring

Division/Halocarbons \& other Atmospheric Trace Species (HATS) group undertakes a flask measurement program at multiple sites globally (see Montzka et al., 2015). Four of these sampling sites are common with the AGAGE network, namely Cape Grim (CGO), American Samoa (SMO), Trinidad Head (THD) and Mace Head (MHD). Detailed comparisons between the NOAA flask results and the AGAGE in situ measurements at the four common sites are undertaken regularly. The table below shows a summary of these comparisons for 3 HCFCs and 4 HFCs used in this study and are expressed as the average ratio of the NOAA over AGAGE results. The ratios listed below are derived by first comparing each individual flask measurement to the closest in situ measurement point (within a specified time window up to 3 hours), at each site; concentration differences and ratios are then found, with outliers those $>3$ sigma from the mean; yearly averages are then calculated for each site giving temporal information; the yearly averages from each site are then averaged to give a single ratio for each year; lastly the average across the whole time period is taken to give the single factor or ratio listed below.

The results show relatively small but consistent differences and no significant temporal trends. Two example figures are given below for HCFC-22 (Fig.S5) and HFC-134a (Fig.S6) showing the average yearly ratios across the comparison sites.

Table S4: Average ratio between NOAA flask results and AGAGE in situ measurements at the common sites for 3 HCFCs and 4 HFCs in this study. The instruments used for the measurements are indicated in parentheses in the respective scale columns. For dates/sites when the AGAGE ADS and Medusa instrumentation were operational, see Table 2 in the main manuscript. For a brief overview of the NOAA instrumentation (M1/M3 \& M2), see Table 1 in Montzka et al. 2015.

\begin{tabular}{|c|c|c|c|c|c|}
\hline Species & $\begin{array}{l}\text { Ratio } \\
\text { (NOAA/AGAGE) }\end{array}$ & $\begin{array}{l}\text { NOAA Scale } \\
\text { (instrument) }\end{array}$ & $\begin{array}{l}\text { AGAGE } \\
\text { Scale } \\
\text { (instrument) }\end{array}$ & Sites used & $\begin{array}{l}\text { Comparison } \\
\text { period }\end{array}$ \\
\hline HCFC-22 & $0.997 \pm 0.003$ & $\begin{array}{l}\text { NOAA-2006 } \\
\text { (M1/M3) }\end{array}$ & $\begin{array}{l}\text { SIO-05 } \\
\text { (ADS/Med) }\end{array}$ & $\begin{array}{l}\text { CGO, SMO, THD, } \\
\text { MHD }\end{array}$ & $1998-2016$ \\
\hline HCFC-141b & $0.994 \pm 0.005$ & $\begin{array}{l}\text { NOAA-1994 } \\
\text { (M1/M3) }\end{array}$ & $\begin{array}{l}\text { SIO-05 } \\
\text { (ADS/Med) }\end{array}$ & $\begin{array}{l}\text { CGO, SMO, THD, } \\
\text { MHD }\end{array}$ & $1998-2016$ \\
\hline HCFC-142b & $0.974 \pm 0.005$ & $\begin{array}{l}\text { NOAA-1994 } \\
\text { (M1/M3) }\end{array}$ & $\begin{array}{l}\text { SIO-05 } \\
\text { (ADS/Med) }\end{array}$ & $\begin{array}{l}\text { CGO, SMO, THD, } \\
\text { MHD }\end{array}$ & $1998-2016$ \\
\hline HFC-134a & $1.001 \pm 0.005$ & $\begin{array}{l}\text { NOAA-1995 } \\
\text { (M1/M3) }\end{array}$ & $\begin{array}{l}\text { SIO-05 } \\
\text { (ADS/Med) }\end{array}$ & $\begin{array}{l}\text { CGO, SMO, THD, } \\
\text { MHD }\end{array}$ & $1998-2016$ \\
\hline HFC-143a & $0.923 \pm 0.008$ & $\begin{array}{l}\text { NOAA-2008 } \\
\text { (M2) }\end{array}$ & $\begin{array}{l}\text { SIO-07 } \\
\text { (Med) }\end{array}$ & CGO, SMO, THD & $2007-2015$ \\
\hline HFC-125 & $0.946 \pm 0.008$ & $\begin{array}{l}\text { NOAA-2008 } \\
\text { (M2) }\end{array}$ & $\begin{array}{l}\text { SIO-14 } \\
\text { (Med) }\end{array}$ & CGO, SMO, THD & 2007-2015 \\
\hline HFC-32 & $0.912 \pm 0.017$ & NOAA (M2) & $\begin{array}{l}\text { SIO-07 } \\
\text { (Med) }\end{array}$ & CGO, SMO, THD & 2009-2015 \\
\hline
\end{tabular}




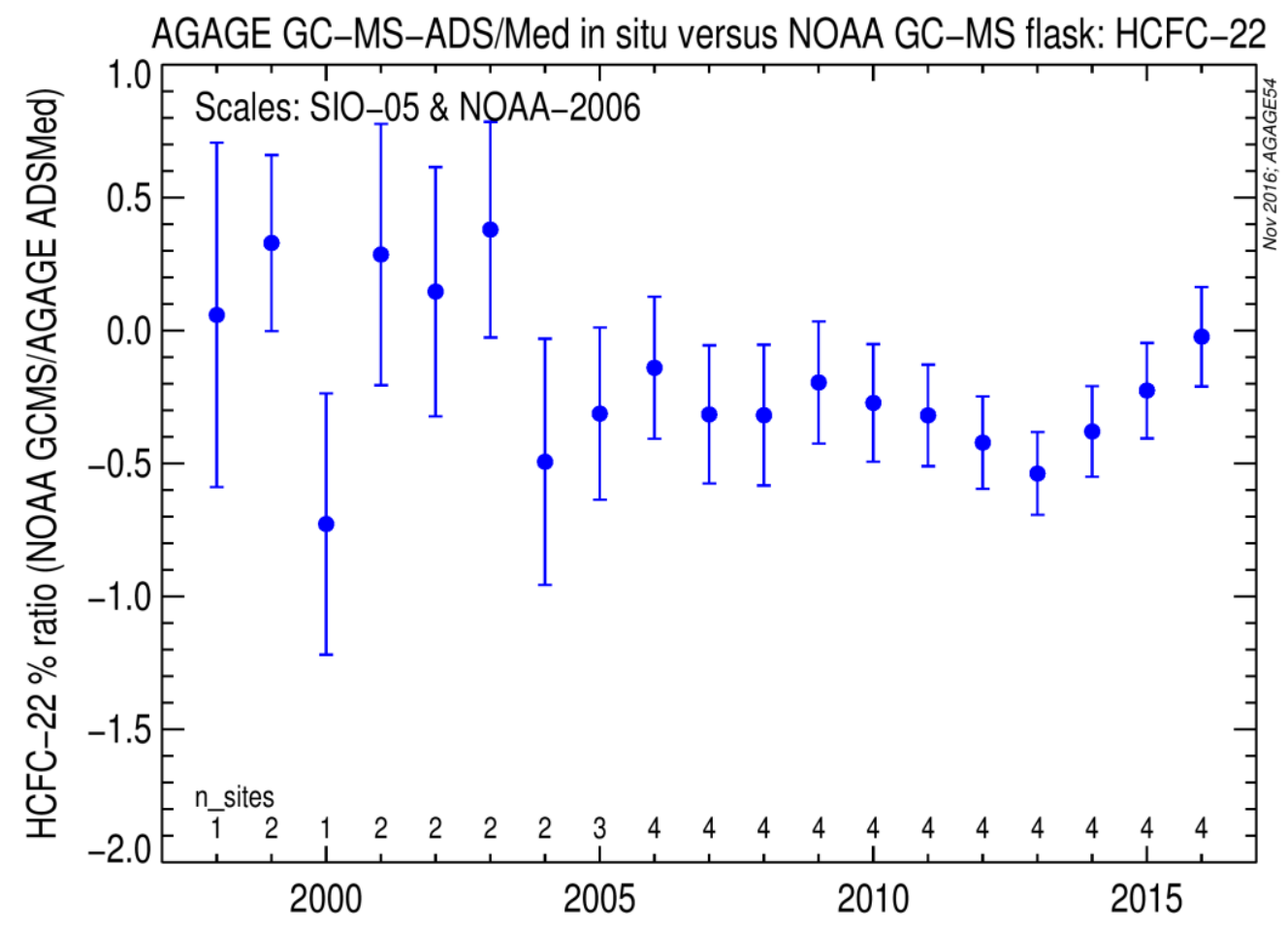

Figure S5. Temporal trend of the NOAA/AGAGE HCFC-22 percentage difference averaged across the common sites. AGAGE GC-MS-ADS data were used up to the end of 2003 at Cape Grim and Mace Head, with GC-MS-Medusa data thereafter. In 2005 and 2006 the GCMS-Medusa instruments became operational Trinidad Head and Samoa, respectively.

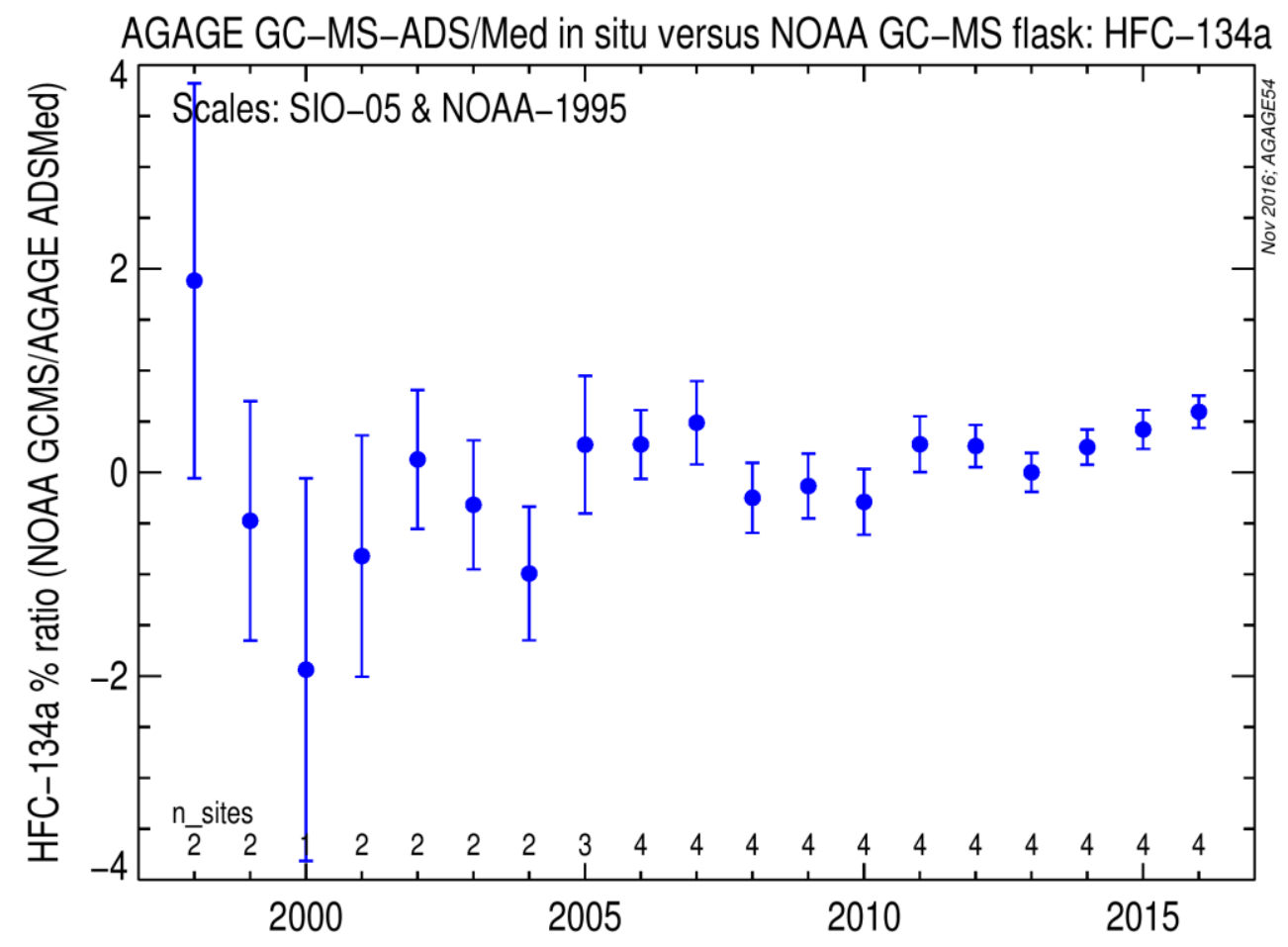

Figure S6: temporal trend of the NOAA/AGAGE HFC-134a percentage difference averaged across the common sites. AGAGE GC-MS-ADS data were used up to the end of 2003 at 
Cape Grim and Mace Head, with GC-MS-Medusa data thereafter. In 2005 and 2006 the GCMS-Medusa instruments became operational Trinidad Head and Samoa, respectively.

References

Montzka, S. A., McFarland, M., Andersen, S.O., Miller, B.R., Fahey, D.W., Hall, B.D., Hu, L., Ciso, C., Elkins, J.W., 2015. Recent Trends in Global Emissions of Hydrochlorofluorocarbons and Hydrofluorocarbons: Reflecting on the 2007 Adjustments to the Montreal Protocol. J. Phys. Chem. A. 2015, 119, 4439-4449. Doi:10.1021/jp50973761. 
Supplementary Material: Percentage difference between the model calculated mole fractions and the observed mole fractions of the HCFCs and HFCs.

Figures (S7-S14) show the percentage difference between the mole fractions derived in the inversion and those observed. The figures show that any long term trends in the residual are small compared to random uncertainties, indicating that the emissions derived in the inversion are consistent with the information provided by the data, chemical transport model and assumed uncertainties.

\section{Figure S7.}

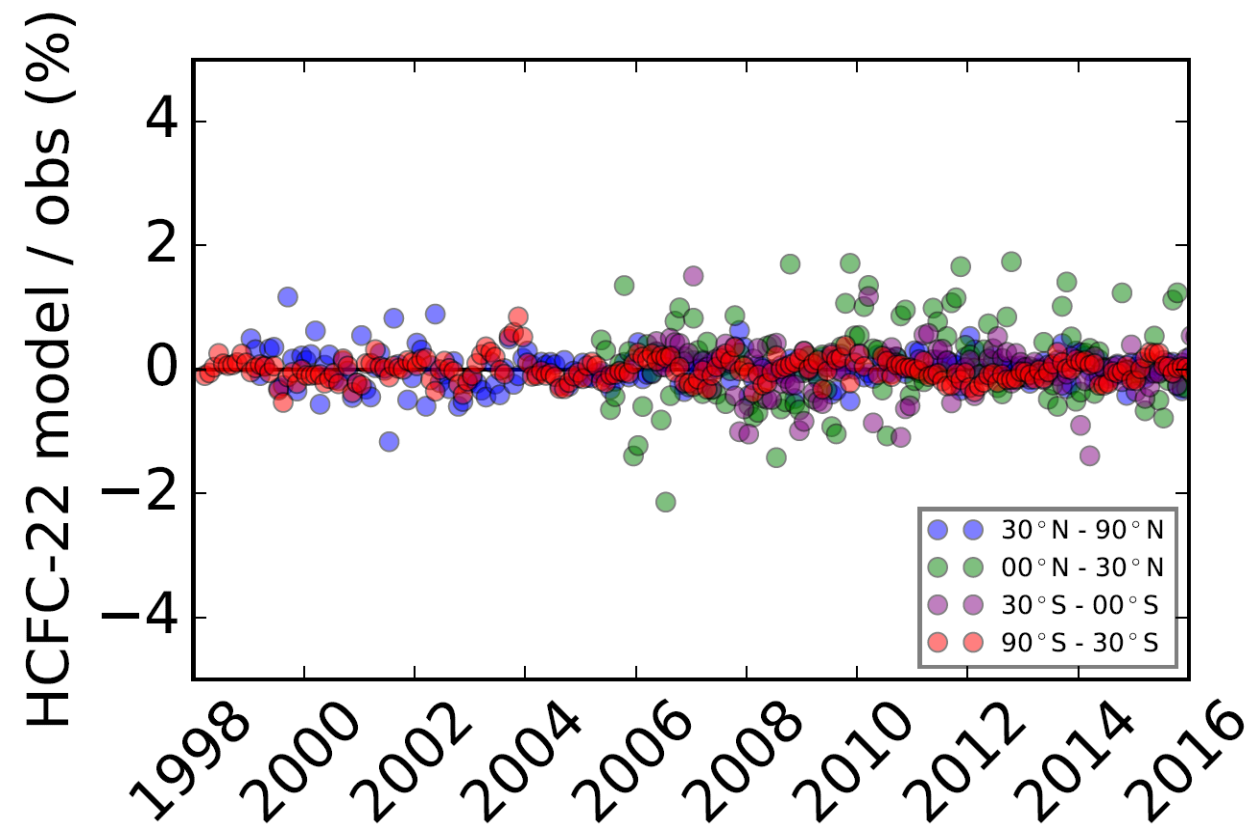


Figure S8

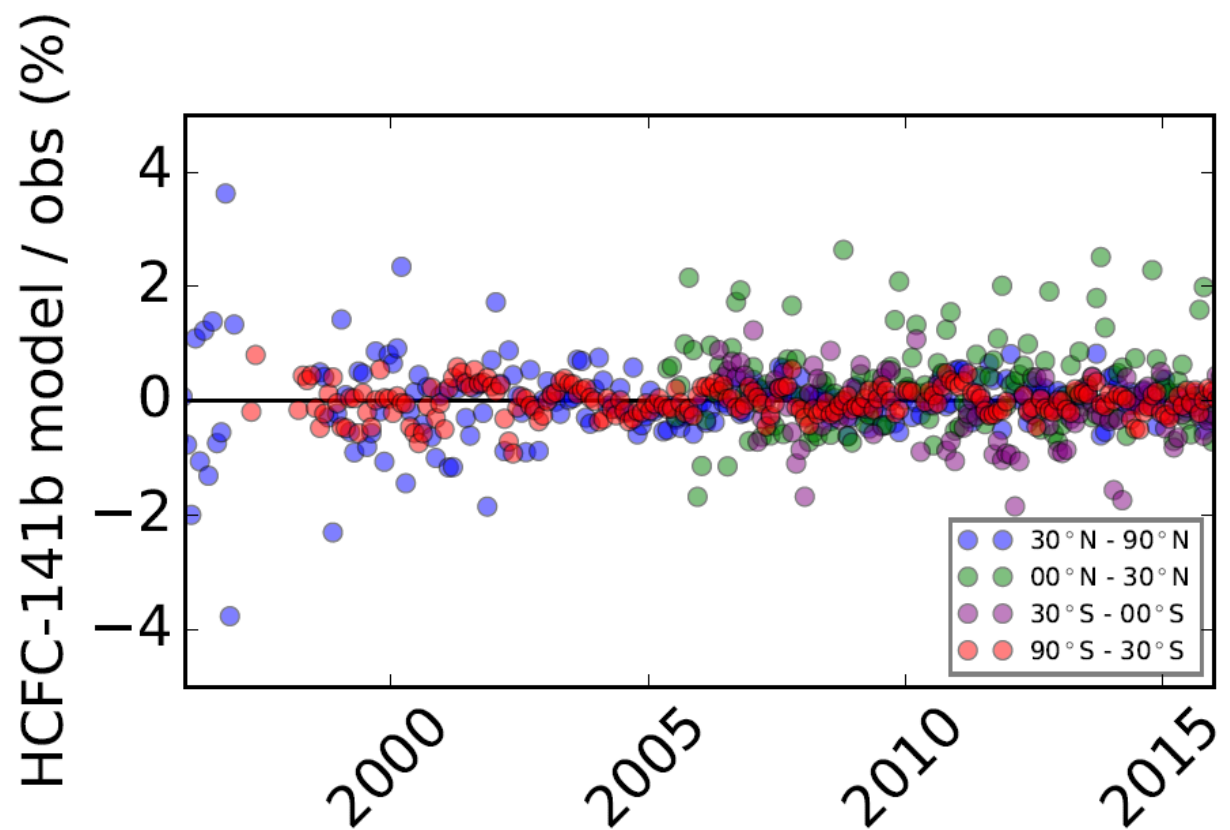

Figure S9.

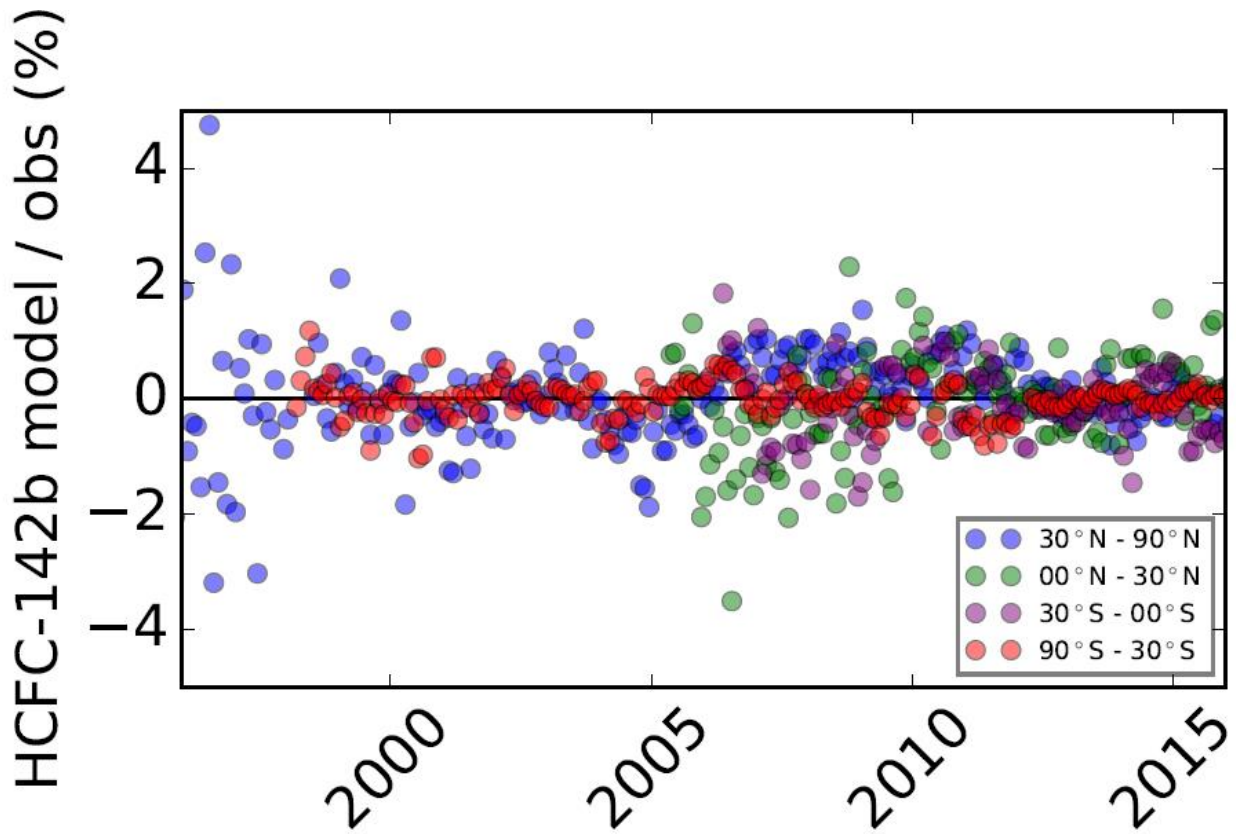


Figure S10.

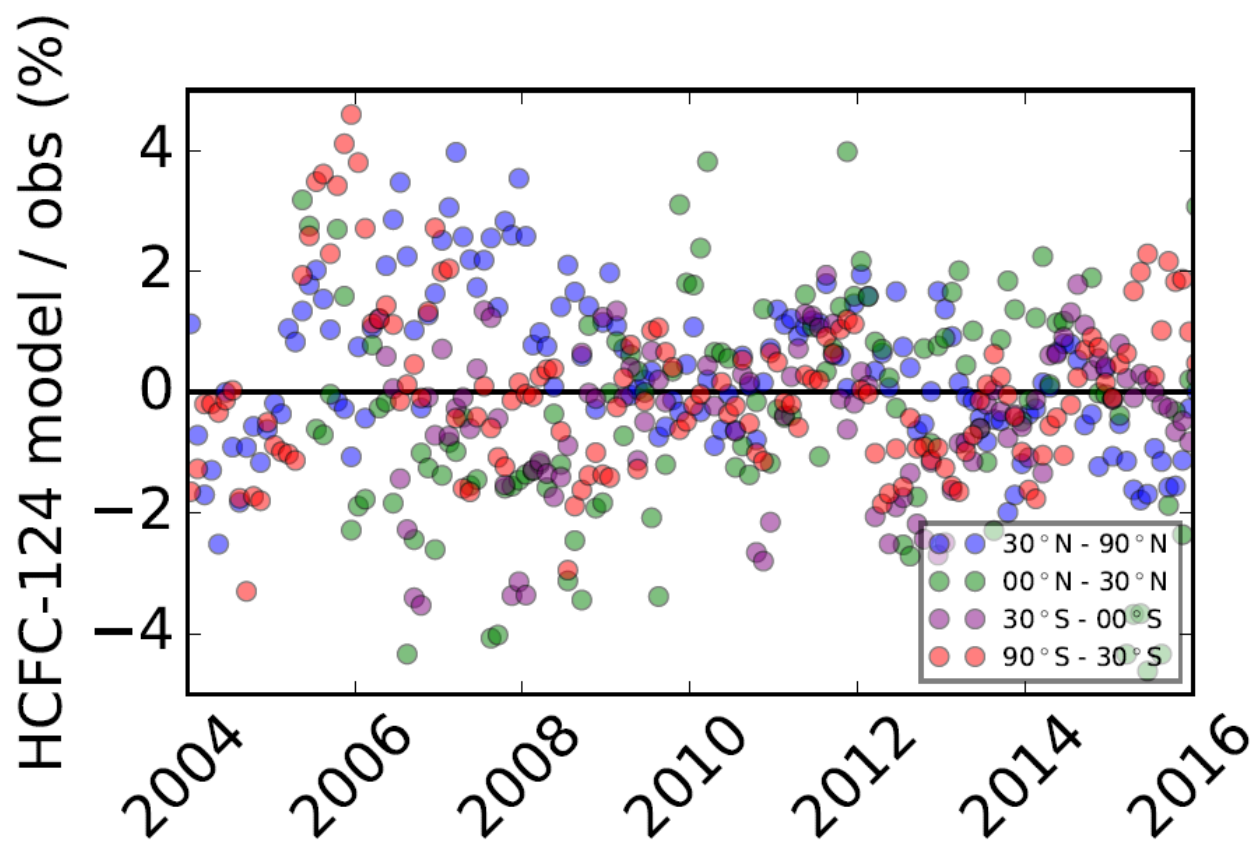

Figure S11.

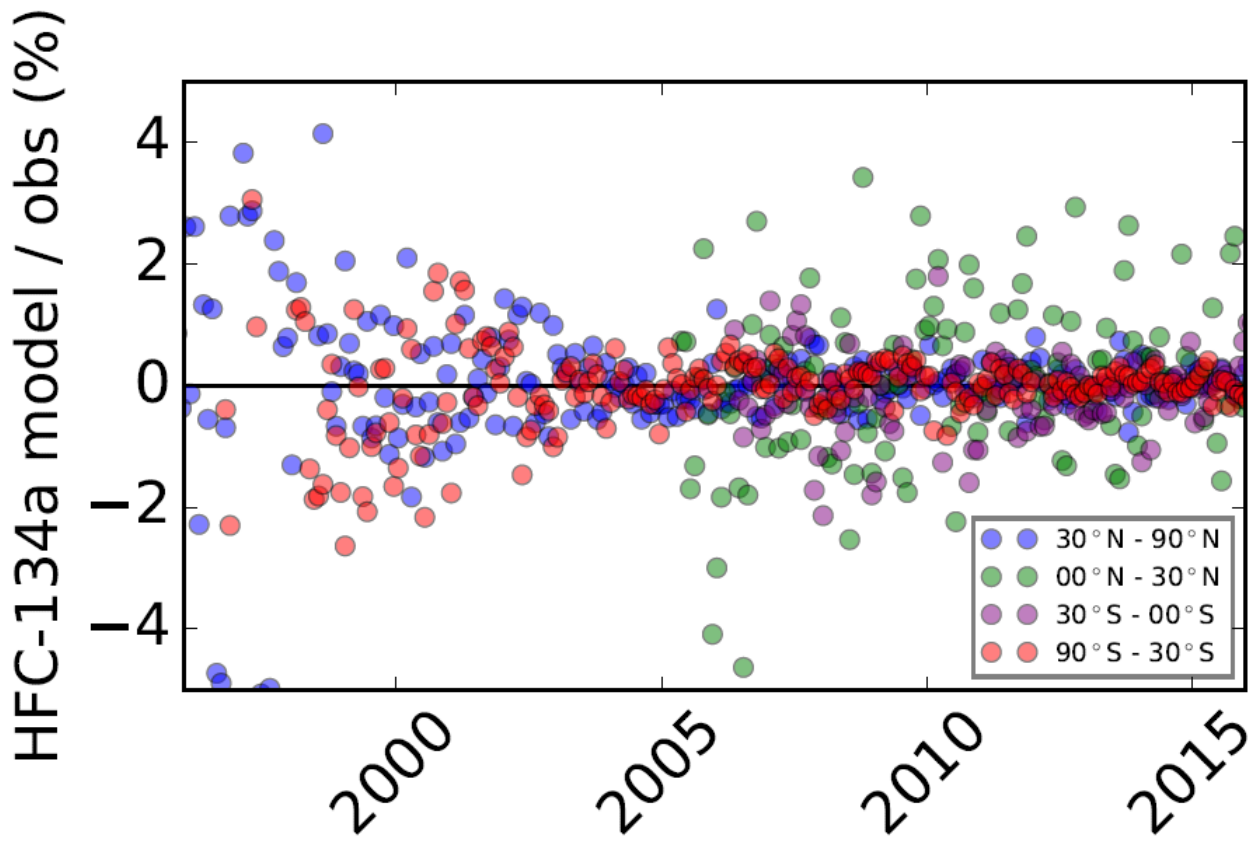


Figure S12.

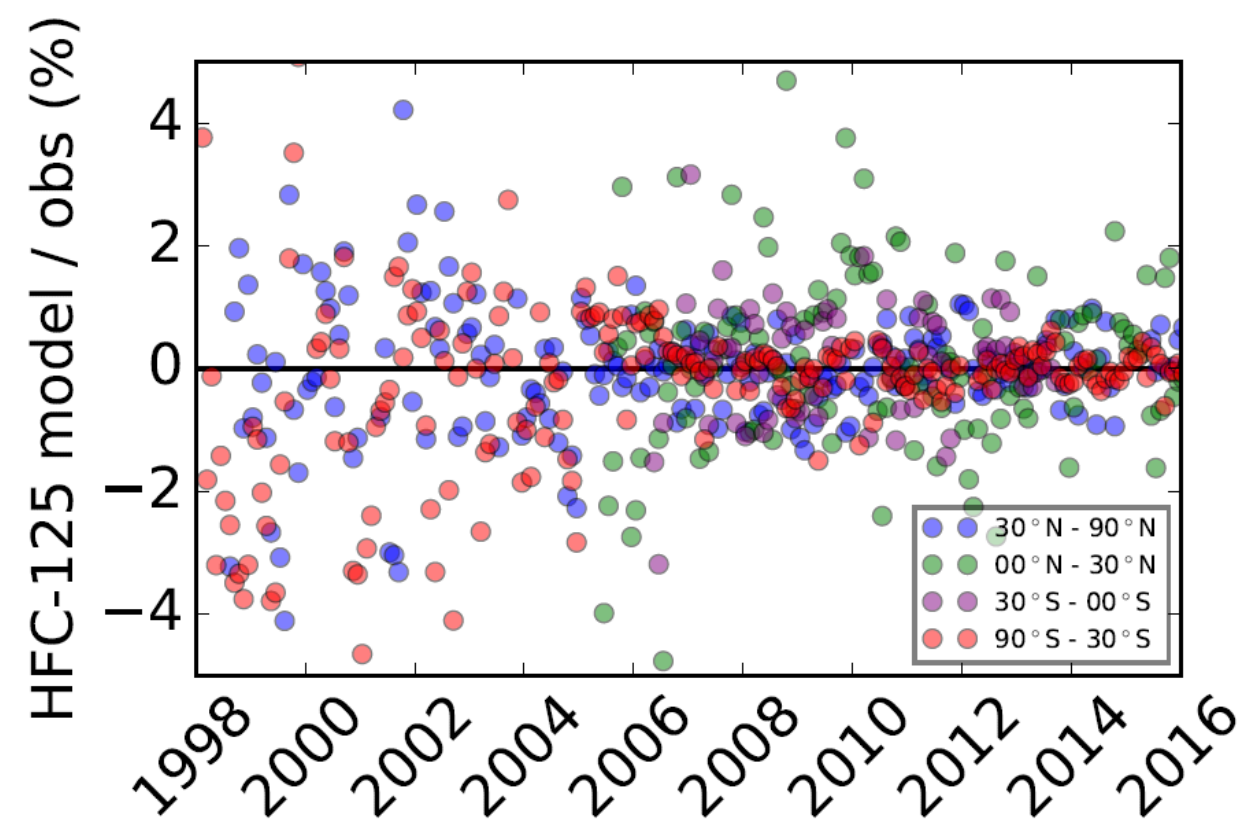

Figure S13

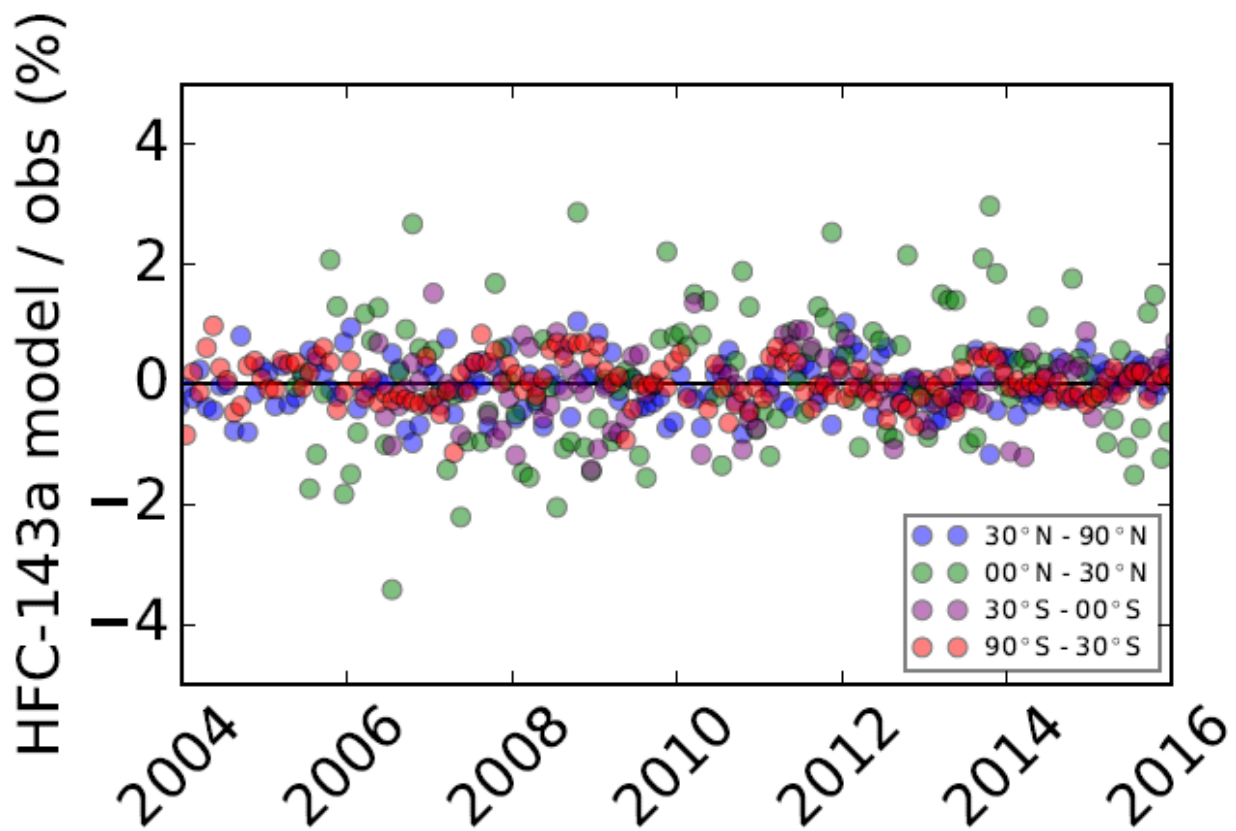


Figure S14

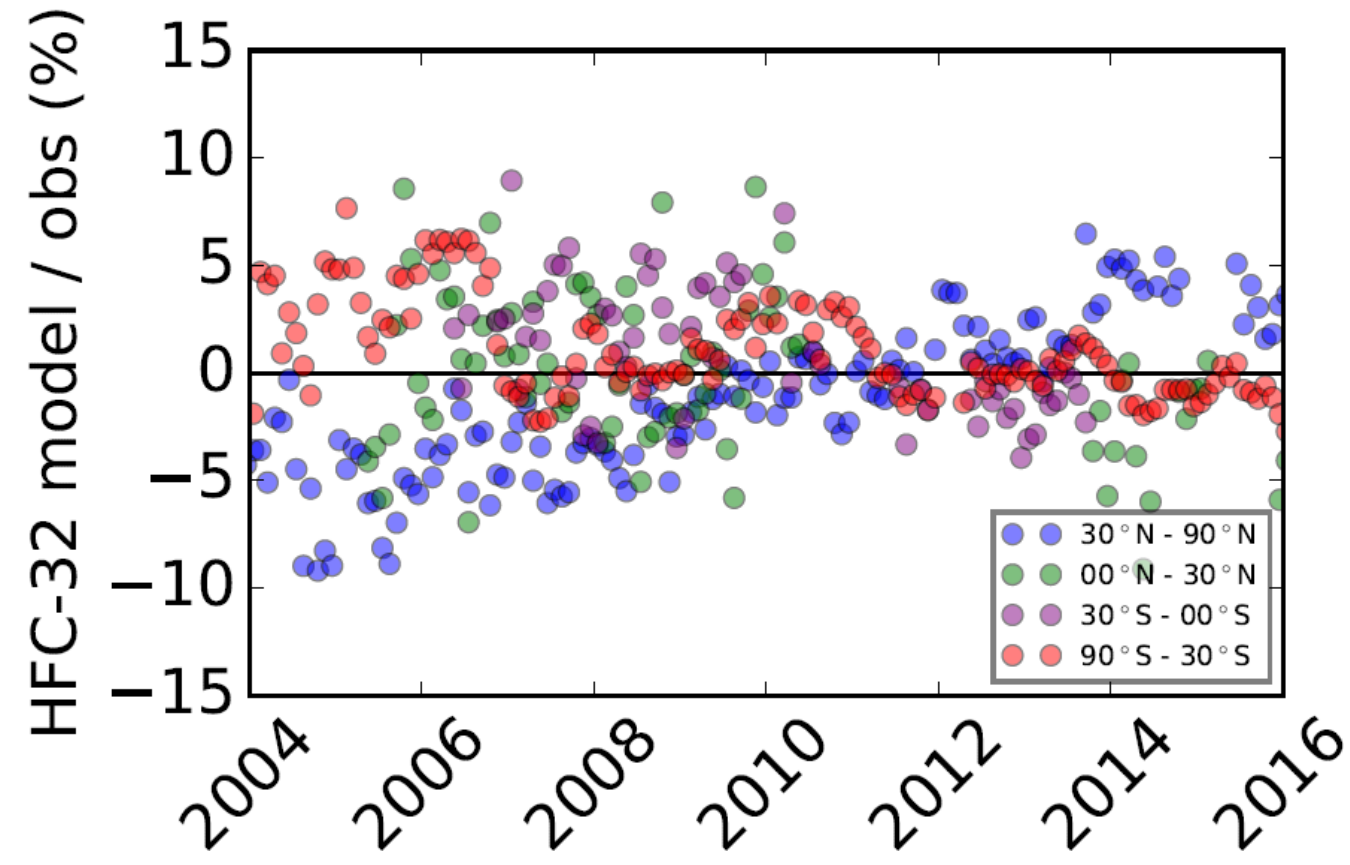

